\title{
Molecular Characterization of Spirometra decipiens Complex (Eucestoda: Diphyllobothriidea) from Uruguay
}

\author{
María Teresa Armúa-Fernández ${ }^{1, * \mathbb{C}}$, Mauricio Burutarán ${ }^{2}$, Valentin Bazzano ${ }^{1}$, María Laura Félix ${ }^{1}$, Oscar Castro ${ }^{3}$ \\ and José Manuel Venzal ${ }^{1}$ (1) \\ 1 Laboratorio de Vectores y Enfermedades Transmitidas, Departamento de Ciencias Biológicas, CENUR Litoral \\ Norte-Salto, Universidad de la República, Rivera 1350, Salto 50000, Uruguay; \\ valentibazzano@gmail.com (V.B.); mlfelix78@hotmail.com (M.L.F.); dpvuru@hotmail.com (J.M.V.) \\ 2 Private Veterinary Practice, Salto 50000, Uruguay; mauricioburutaran@gmail.com \\ 3 Departamento de Parasitología Veterinaria, Instituto de Patobiología, Facultad de Veterinaria, Universidad de \\ la República, Montevideo 11600, Uruguay; oscarfcastro2064@gmail.com \\ * Correspondence: m.teresa.armua@gmail.com
}

check for updates

Citation: Armúa-Fernández, M.T.; Burutarán, M.; Bazzano, V.; Félix, M.L.; Castro, O.; Venzal, J.M. Molecular Characterization of Spirometra decipiens Complex (Eucestoda: Diphyllobothriidea) from Uruguay. Taxonomy 2021, 1, 270-277. https: / / doi.org/10.3390/taxonomy 1030021

Academic Editor: Peter Michalik

Received: 7 June 2021

Accepted: 14 September 2021

Published: 21 September 2021

Publisher's Note: MDPI stays neutral with regard to jurisdictional claims in published maps and institutional affiliations.

Copyright: (c) 2021 by the authors. Licensee MDPI, Basel, Switzerland. This article is an open access article distributed under the terms and conditions of the Creative Commons Attribution (CC BY) license (https:/ / creativecommons.org/licenses/by/ $4.0 /)$.

\begin{abstract}
This study used a partial sequence of the mitochondrial cox1 gene for the reconstruction of the interrelationship of the adult and larval stages of Spirometra obtained from Cerdocyon thous, Leopardus munoai, Canis familiaris, Didelphis albiventris and Philodryas patagoniensis in Uruguay. The phylogenetic analysis showed that they were grouped with Spirometra decipiens from the Americas with a high bootstrap support. According to recent studies, American Spirometra species split into two $S$. decipiens complexes. Our findings strongly suggest that $S$. decipiens complex 1 is widely distributed in South America, and that wild and domestic canids are definitive hosts. Most of the samples $(n=10)$ grouped adults and plerocercoids that were retrieved from mammals and reptiles and seem to be the same taxon found in a Lycalopex gymnocercus from Argentina. A second clade was formed with Spirometra sp. found in a L. munoai as well as other wild felids such as a Puma concolor and a Leopardus pardalis (both from Argentina). On the other hand, S. decipiens complex 2 is present in South America and North America. South American clade parasitizes wild (and possibly domestic) felids and reptiles as definitive and intermediate hosts, respectively, whereas the North American clade found in snakes and captive meerkats (acting either as second intermediate or paratenic hosts) has unconfirmed definitive hosts.
\end{abstract}

Keywords: Spirometra decipiens; cox1 gene; phylogeny; South America; Uruguay

\section{Introduction}

Adenocephalus Nybelin, 1931, Diphyllobothrium Cobbold, 1858, Dibothriocephalus Lühe, 1899, and Spirometra Faust, Campbell \& Kellogg, 1929 (Eucestoda: Diphyllobothriidea), are cestodes that are greatly important to public health and veterinary medicine [1]. Diphyllobotriids parasitize a wide range of vertebrates; however, the first stage (coracidium) needs an aquatic environment, where soon after entering its intermediate hosts (copepods) develops into a procercoid. Diphyllobothrium spp., Adenocephalus spp. and Dibothriocephalus spp. develop into the second larval stage (plerocercoid) in fish. A wide range of fish-eating mammals and birds are listed as the definitive hosts [2]. Moreover, these three genera are capable of infecting humans, developing the adult stage in the small intestine and causing a disease known as diphyllobothriosis [3]. The Spirometra spp. life cycle includes aquatic and terrestrial tetrapods (reptiles, amphibians, and mammals) that can harbor the plerocercoids. In this case, definitive hosts are mainly domestic and wild carnivores (canids, felids, etc.) that prey on the intermediate or paratenic hosts. In humans, the disease produced by the development of the Spirometra's plerocercoids is known as sparganosis [4,5]. In rare cases, the adult stage of Spirometra spp. can develop in the human intestine, developing spirometrosis [3]. 
To date, the knowledge of Spirometra taxonomy is yet to be elucidated [2]. In a recent report, Kuchta et al. [5] proposed a classification with at least six molecularly distinct taxa according to their geographical distribution and molecular phylogeny. Spirometra mansoni has the widest distribution around the Old World and Oceania, Spirometra erinaceieuropaei in Europe, Spirometra folium in Africa, a Spirometra sp. reported in Japan and Korea, and Spirometra decipiens split into two complexes that are distributed within the Americas. Due to the similarities among adults and larval stages, it is imperative to combine morphological and molecular approaches for species determination of these taxa [2]. Oda et al. [6] compiled the findings of adults and plerocercoids of the genus Spirometra parasitizing vertebrates from different parts of South America. Molecular approaches by several authors reported that $S$. decipiens found in the Americas clearly differentiate from all Asian isolates of S. mansoni, which are identified under several incorrect names and are closely related to a single sequence of Sparganum proliferum from Venezuela [1,7-9]. In addition, Yamasaki et al. [10] reinforced the assumption that the two types of Asian Spirometra are distinct as S. erinaceieuropaei and S. decipiens.

In Uruguay, there are several morphology-based reports of diphyllobothriideans. Adult tapeworms in stray dogs had been reported as Diphyllobothrium sp. from different areas of the Montevideo Department, and other dogs from rural areas in different parts of Uruguay [11,12]. In contrast, Spirometra tapeworms have been found in domestic dogs and cats $[13,14]$, as well as in wild carnivores such as Geoffroy's cat (Leopardus geoffroyi d'Orbigny \& Gervais, 1844), Crab-eating fox (Cerdocyon thous Linnaeus, 1766) and Pampas fox (Lycalopex gymnocercus Fisher 1814) [15]. Meanwhile, plerocercoides were retrieved from several amphibians, reptiles, and mammals, as well as one bird species [8,16-19]. Moreover, two human cases of sparganosis have been reported from Uruguay $[4,20]$.

The objective of this study was the molecular characterization of the adult and larval stages of Spirometra spp. in definitive and intermediate host samples from Uruguay.

\section{Materials and Methods}

\subsection{Ethics Concerning Wild Animal Samples}

All wild animals included in this study were roadkill, and their carcasses were collected along the main routes.

\subsection{Sampling}

The tapeworms were searched in the small intestines of the carcasses of four carnivore species: C. thous, L. gymnocercus, L. geoffroyi and Uruguayan Pampas cat (Leopardus munoai Ximenez, 1961). Samples obtained from domestic dogs were collected from feces after spontaneous elimination of the tapeworms. Likewise, plerocercoids were obtained from subcutaneous tissue, muscles, and mesenteries of Patagonian Green Racer (Philodryas patagoniensis, Girard, 1858) and White-eared opossum (Didelphis albiventris Lund, 1840) (Table 1). All cestodes were collected in plastic recipients containing ethanol $70^{\circ}$ and stored at $4{ }^{\circ} \mathrm{C}$ until used. One specimen (adult or plerocercoid) from each host was used for DNA extraction. 
Table 1. Data of hosts and diphyllobothriidean samples used in this study.

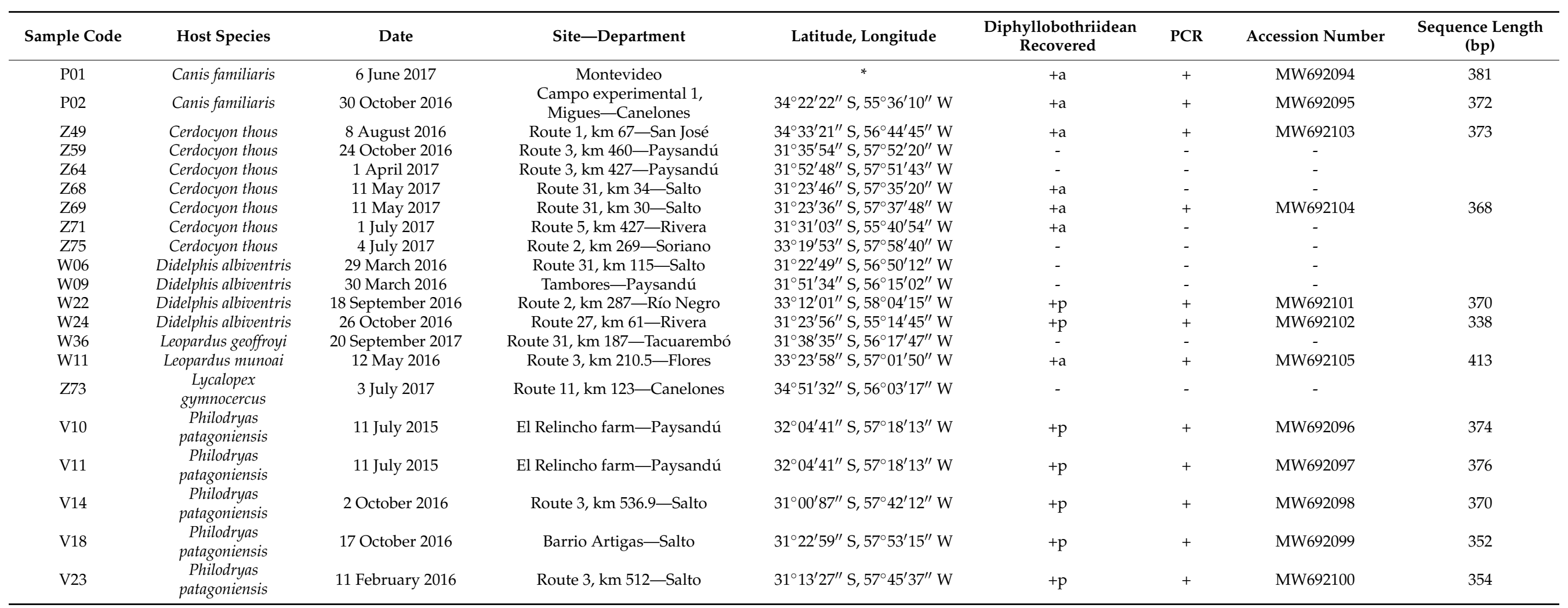

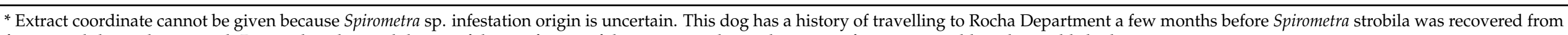
feces. a: adult, p: plerocercoid. Due to the advanced degree of decay of some of the carcasses, the total amount of parasites could not be established. 


\subsection{DNA Extraction, PCR and Sequencing}

DNA was extracted using a commercial GeneJET Genomic DNA Purification Kit (Thermo Scientific, Vilnius, Lithuania) following manufacturer instructions. The PCR used for the molecular identification of diphyllobothriideans amplified a region of approximately $446 \mathrm{bp}$ of cox1 (cytochrome oxidase subunit 1) gene in platyhelminths [21]. The DNA of the diphyllobothriideans was amplified by PCR using primers 2575 (TTT TTT GGG CAT CCT GAG GTT TAT) and 3021 (TAA AGA AAG AAC ATA ATG AAA ATG Y). A positive (Echinococcus granulosus sensu stricto) and negative (DNAse-free water) control were included in each reaction. PCR products were visualized under UV transillumination in a 1.5\% agarose gel stained with GoodView ${ }^{\mathrm{TM}}$ Nucleic Acid Stain (Beijing SBS Genetech Co., Ltd., Beijing, China). Amplicons of the expected size were purified using a GeneJET PCR Purification Kit (Thermo Scientific, Vilnius, Lithuania) and sent to a commercial sequencing company (Macrogen Inc., Seoul, Korea).

\subsection{Phylogenetic Analyses}

All the alignments were performed using MEGA 7 [22]. Each sequence was carefully checked, and manual corrections were carried out when necessary. The complementary obtained sequences for each sample were aligned, and consensus sequences were generated. For phylogenetic tree construction, the sequences obtained in this study were aligned with the other members of the genera Spirometra sequences retrieved from GenBank using the MUSCLE algorithm. A phylogeny was constructed using the maximum likelihood (ML) algorithm [22] and the Bayesian method (BI) [23]. The best-fitting evolutionary model for cox1 gene was Hasegawa-Kishino-Yano with gamma distribution. The support of the internal branching of the ML tree was assessed using 1000 bootstrap replicates. For the BI tree, four independent Markov chains ran for 1,000,000 Metropolis-coupled MCMC generations, beginning with random seeds, and ran four times, sampling a tree every 100 th generations. The first $25 \%$ of the trees were considered as burn-in. The remaining trees were employed to calculate the Bayesian posterior probability. Schistocephalus solidus (AP017669) was used as the outgroup in both approaches.

\section{Results}

\subsection{Samples}

A total of 16 mammals and five reptiles were processed. The mammals were: one L. gymnocercus, seven C. thous, one L. geoffroyi, one L. munoai, four D. albiventris and two domestic dogs. In the case of reptiles, all samples were collected from P. patagoniensis (Table 1). Four of the C. thous and the L. munoai harbored diphyllobothriidean adults in the small intestine. Spontaneously eliminated diphyllobothriidean adults were also obtained from the feces of two dogs. Partial segments of the strobila imbibed in ethanol $95^{\circ}$ of both specimens collected from the dogs (P01, P02) were deposited in the Helminthological Collection of Museo Nacional de Historia Natural de Montevideo (MNHNM), Uruguay, under the numbers, MNHNM 4220 and MNHNM 4221, respectively.

Plerocercoids were obtained from the mesentery and abdominal muscle walls from two of the four $D$. albiventris analyzed. Likewise, plerocercoids from all $P$. patagoniensis $(n=5)$ were retrieved from the subcutaneous, muscle and organ walls.

\subsection{PCR and Sequencing}

Adults or plerocercoids were found in 14 out of the 21 analyzed vertebrates. Amplicons were obtained from 12 of the 14 samples (Table 1). All the sequences obtained from both adults and plerocercoids were confirmed to be members of the genus Spirometra. The samples of plerocercoids V10, V11, V14, V23, W22 and W24 and of adults Z49, Z68, P01 and P02 had a high identity (between 98 and 99\%) with a sample obtained from L. gymnocercus from Argentina (KF572950). Furthermore, sample W24 had a 97\% identity with samples of a Horay fox (Lycalopex vetulus Lund, 1842) (KT375457) and a plerocercoid of Crotalus sp. (KT375456), both from Brazil. On the other hand, the V18 plerocercoid sample had 99\% and 
94\% identity with samples from ocelots (Leopardus pardalis Linnaeus, 1758) in the States of Pará and Minas Gerais, Brazil (KF40506 and KF40507, respectively). The sequence obtained from the adult cestode retrieved from L. munoai showed an identity of $99 \%$ with eggs shedding by a cougar (Puma concolor Linnaeus, 1771) from Argentina (MH892077).

\subsection{Phylogenetic Analyses}

The final alignment consisted of 63 Spirometra sequences and one of Sch. solidus. The lengths of the sequences range between 178 and $1566 \mathrm{bp}$. For the tree construction, uncharacterized regions of partial sequences were encoded as missing data. Both phylogenetic analyses showed that the Spirometra spp. sequences obtained in this study were grouped with $S$. decipiens from the Americas with a high bootstrap support. Branch support values for both approaches (ML and BI) were included in Figure 1.

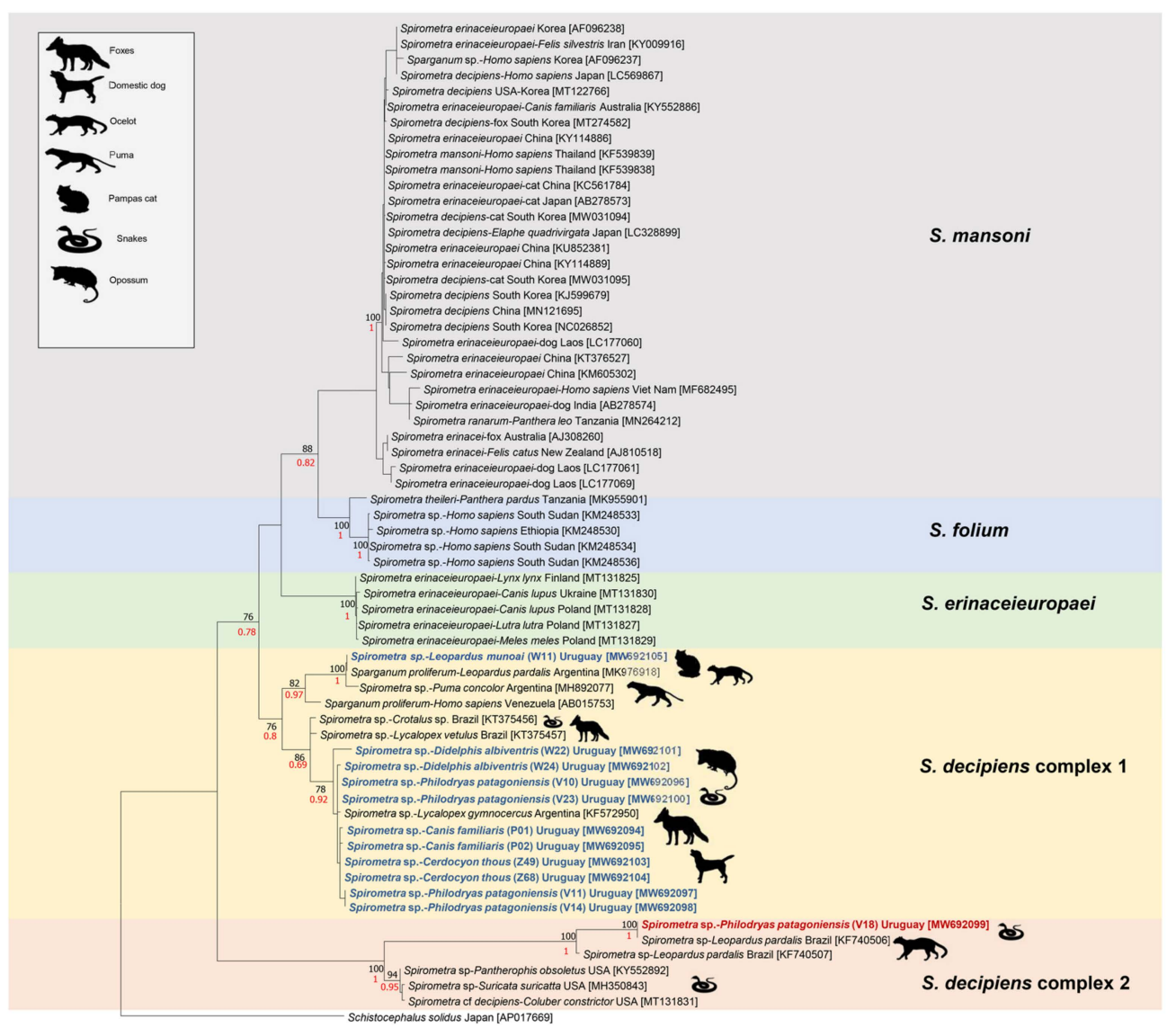

Figure 1. Maximum likelihood tree constructed for the genus Spirometra partial cox1 gene sequences. Numbers represent bootstrap support generated from 1000 replicates, and only branches supporting values $>70$ are shown. Bayesian tree support values are highlighted in red. The sequences obtained in this study were highlighted in bold and assigned a distinct color. GenBank accession numbers are in brackets. Each sequence was included with its original registered name. However, each Spirometra recognized species was given a different color. Sch. solidus was included as outgroup.

\section{Discussion}

To date, the reports of diphyllobothriideans in Uruguay have been based on the identification of eggs, plerocercoids and adult specimens purely by morphology $[7,12,14,19]$. Due to the morphological similarities of both adults and larval forms that hinder a precise taxonomic identification, Kuchta et al. [2] recommend the combined use of molecular and morphological features to characterize the diphyllobothriideans tapeworms. For this reason, the most recent works on the genus Spirometra have been based on molecular methods where partial sequences of genes such as cox1 were studied. Based on this, 
Almeida et al. [8] report the occurrence of at least two species of Spirometra in South America, which are different from Old World taxa. In the most recent reports [5,9], American Spirometra species are split into two $S$. decipiens complexes.

The results obtained herein revealed that all partial sequences obtained for the cox1 gene belonged to genus Spirometra and were related to taxa previously found in the Americas. By comparing the sequences with those registered in GenBank, the presence of both S. decipiens complexes were determined (Figure 1).

Ten of our sequences grouped with a Spirometra sp. sequence from L. gymnocercus from Argentina [24]. This result was in concordance with previous reports where adults of Spirometra sp. were found in foxes, as well as in dogs in Uruguay and southern Brazil $[7,15,25]$. This clade also was related with Spirometra sp. sequences obtained from $L$. vetulus and from a Crotalus durissus from Brazil [7].

It is likely, therefore, that New World foxes (for example, C. thous, L. gymnocercus and $L$. vetulus) and dogs (probably from rural areas) prey on plerocercoid-infected reptiles (snakes), frogs, didelphid marsupials or other vertebrates, developing the adult form in their small intestine.

Philodryas patagoniensis, as well as D. albiventris, have a diet that includes a wide variety of small vertebrates [26]. Although it has not yet been elucidated which role these two hosts play in the Spirometra spp. lifecycle, there are two possible scenarios for P. patagoniensis and D. albiventris infestation with Spirometra plerocercoids. First, they could be infected by ingesting small vertebrates housing plerocercoids (second intermediate or paratenic hosts); in which case, they would act as paratenic hosts. The other scenario could involve drinking water with copepods harboring procercoids (first intermediate hosts); in which case, they would play the role of second intermediate hosts.

The other clade among S. decipiens complex 1 was formed with Spirometra retrieved from wild felids, L. munoai, P. concolor and L. pardalis (these two latter from Argentina) [27]. Although Arrabal et al. [27] registered diphyllobothriideans adults and eggs as Sparganum proliferum, this is the denomination for a larval stage; consequently, the adult stage and its products (eggs) should be named as Spirometra sp. Phylogenetically, this taxon seemed to be closer to Spirometra sp. reported herein than to Sparganum proliferum reported from the Venezuelan patient. These findings support the McHale et al. [9] studies describing that S. decipiens complex 1 is formed by several cryptic species involving wild and domestic carnivores as definitive hosts throughout the Americas. Furthermore, our findings strongly suggest that $S$. decipiens complex 1 is widely distributed in South America and that wild and domestic canids, as well as wild (and possibly domestic) felids, are the definitive hosts.

A separate clade was found in a sample of a plerocercoid obtained from a P. patagoniensis (V18), which was collected in the surroundings of Salto city. The sequence of this sample had a high percentage of identity (94-99\%) with sequences of Spirometra sp. from two specimens found in ocelots (L. pardalis) from Brazil [8]. Moreover, this taxon showed to be highly related to the Spirometra sp. plerocercoids retrieved form captive Suricata suricatta Schreber, 1776, Coluber constrictor Linnaeus, 1758 and Pantherophis obsoletus Say, 1823 from the USA. Until now, the only confirmed definitive hosts for this Spirometra sp. clade are ocelots (L. pardalis) from Brazil. Perhaps, in Uruguay, wild felids could also be the definitive hosts of $S$. decipiens complex 2 . However, this could not be confirmed since the only L. geoffroyi examined did not harbor diphyllobothriideans, and the L. munoai harbored a molecularly distinct Spirometra.

According to the phylogenetical analysis presented herein, S. decipiens complex 2 appeared to be formed by two taxa. A South American clade, involving wild (and possibly domestic) felids and reptiles as definitive and intermediate hosts, respectively, and a North American clade found in snakes and captive meerkats, acting either as second intermediate or paratenic hosts, with an unconfirmed definitive host.

The South American wild canid and felid hosts seem to harbor different taxa (one the canids and two the felids) of the genus Spirometra (Figure 1). Adaptation to a domestic cycle of theses taxa is more likely since samples from the domestic dogs analyzed in this 
study were grouped with those of wild canids. Nonetheless, there is a lack of molecular information about Spirometra sp. parasitizing domestic cats. Therefore, the dichotomy reflecting host specificity cannot be elucidated until more samples from domestic carnivores are analyzed.

Further studies combining molecular and morphological features from wild hosts, as well as including samples from other hosts, such as humans and domestic carnivores, are needed for progressing in the specific determination of these cestodes. Those studies would be of a great value for determining the zoonotic potential of the different Spirometra species [2].

Author Contributions: M.T.A.-F.: Conceptualization, Data Curation, Methodology, Formal Analysis, Investigation, Project Administration, Writing — Original Draft, Writing—Review and Editing; M.B.: Data Curation, Methodology, Investigation; V.B.: Data Curation, Methodology, Investigation; M.L.F.: Methodology, Formal Analysis, Investigation, Writing—Review and Editing; O.C.: Conceptualization, Methodology, Formal Analysis, Investigation, Writing_Review and Editing; J.M.V.: Conceptualization, Methodology, Formal Analysis, Investigation, Writing—Original Draft, Writing-Review and Editing. All authors have read and agreed to the published version of the manuscript.

Funding: This research received no external funding.

Institutional Review Board Statement: Not applicable.

Informed Consent Statement: Not applicable.

Data Availability Statement: All data presented in this study are available in the article.

Acknowledgments: We would like to thank Luis Carvalho and Oscar Correa for their help during the sample collection. We also would like to thank Wilson S. Serra (Museo Nacional de Historia Natural, Montevideo, Uruguay) for his collaboration. Moreover, we want to thank Sebastián Muñoz-Leal (Universidad de Concepción, Chile) for his collaboration in the construction of the BI tree.

Conflicts of Interest: The authors declare no competing interest in the study.

\section{References}

1. Waeschenbach, A.; Brabec, J.; Scholz, T.; Littlewood, D.T.J.; Kuchta, R. The catholic taste of broad tapeworms-multiple routes to human infection. Int. J. Parasitol. 2017, 47, 831-843. [CrossRef]

2. Kuchta, R.; Scholz, T.; Brabec, J.; Narduzzi-Wicht, B. Diphyllobothrium, Diplogonoporus and Spirometra. In Biology of Foodborne Parasites. Section III Important Foodborne Parasites; Xiao, L., Ryan, U., Feng, Y., Eds.; CRC Press: Boca Raton, FL, USA, 2015; pp. 299-326.

3. Scholz, T.; Kuchta, R.; Brabec, J. Broad tapeworms (Diphyllobothriidae), parasites of wildlife and humans: Recent progress and future challenges. Int. J. Parasitol. Parasites Wildl. 2019, 9, 359-369. [CrossRef] [PubMed]

4. Sakamoto, T.; Gutierrez, C.; Rodriguez, A.; Sauto, S. Testicular sparganosis in a child from Uruguay. Acta Trop. 2003, 88, 83-86. [CrossRef]

5. Kuchta, R.; Kołodziej-Sobocińska, M.; Brabec, J.; Młocicki, D.; Sałamatin, R.; Scholz, T. Sparganosis (Spirometra). In Europe in the molecular era. Clin. Infect. Dis. 2021, 72, 882-890. [CrossRef] [PubMed]

6. Oda, F.H.; Borteiro, C.; da Graça, R.J.; Tavares, L.E.R.; Crampet, A.; Guerra, V.; Lima, F.S.; Bellay, S.; Karling, L.C.; Castro, O.; et al. Parasitism by larval tapeworms genus Spirometra in South American amphibians and reptiles: New records from Brazil and Uruguay, and a review of current knowledge in the region. Acta Trop. 2016, 164, 150-164. [CrossRef] [PubMed]

7. Miyadera, H.; Kokaze, A.; Kuramochi, T.; Kita, K.; Machinami, R.; Noya, O.; de Noya, B.A.; Okamoto, M.; Kojima, S. Phylogenetic identification of Sparganum proliferum as a pseudophyllidean cestode by the sequence analyses on mitochondrial COI and nuclear sdhB genes. Parasitol. Int. 2001, 50, 93-104. [CrossRef]

8. Almeida, G.G.; Coscarelli, D.; Melo, M.N.; Melo, A.L.; Pinto, H.A. Molecular identification of Spirometra spp. (Cestoda: Diphyllobothriidae) in some wild animals from Brazil. Parasitol. Int. 2016, 65, 428-431. [CrossRef]

9. McHale, B.; Callahan, R.T.; Paras, K.L.; Weber, M.; Kimbrell, L.; Velázquez-Jiménez, Y.; McManamon, R.; Howerth, E.W.; Verocai, G.G. Sparganosis due to Spirometra sp. (cestoda; Diphyllobothriidae) in captive meerkats (Suricata suricatta). Int. J. Parasitol. Parasites Wildl. 2020, 13, 186-190. [CrossRef]

10. Yamasaki, H.; Sanpool, O.; Rodpai, R.; Sadaow, L.; Laummaunwai, P.; Un, M.; Thanchomnang, T.; Laymanivong, S.; Pa Pa Aung, W.; Intapan, P.M.; et al. Spirometra species from Asia: Genetic diversity and taxonomic challenges. Parasitol. Int. 2021, 80, 1-8. [CrossRef] [PubMed]

11. Holcman-Spector, B.; Olagüe, G.; Couto, A. Helmintiasis del perro vagabundo (Canis familiaris) en la ciudad de Montevideo. Revista Uruguaya Patología Clínica 1985, 21, 67-73. 
12. Sampaio, I.; Castro, E.; Chifflet, L.; Areosa, O. Hallazgo de Diphyllobothrium sp. en Canis familiaris. Veterinaria (Montev.) 1992, 28, 22-23.

13. Osimani, J.J.; Dei-Cas, E.V. Sobre la obtención experimental de Spirometra sp. (Cestoda-Dibothriocephalidae). Neotropica 1974, 20, 57-63.

14. Castro, O.; Venzal, J.M.; Felix, M.L. Two new records of helminth parasites of domestic cat from Uruguay: Alaria alata (Goeze, 1782) (Digenea, Diplostomidae) and Lagochilascaris major Leiper, 1910 (Nematoda, Ascarididae). Vet. Parasitol. 2009, 160, 344-347. [CrossRef]

15. Castro, O.; Venzal, J.M.; Morgades, D.; Katz, H.; Gagliardi, F.; Benítez, G. Algunos helmintos nuevos para Uruguay registrados en la Colección de Helmintos Parásitos de Fauna Silvestre del Departamento de Parasitología, Facultad de Veterinaria, UdelaR. In Proceedings of the V Jornadas Técnicas de la Facultad de Veterinaria, Universidad de la República, Montevideo, Uruguay, 21-23 November 2007; V063 JORr, p. 37.

16. Vogelsang, E.G. La presencia de un sparganum en las ranas (Leptodactylus ocellatus) del Uruguay. Rev. Med. Vet. $1925,2,301$.

17. Wolffhügel, K.; Vogelsang, E.G. Dibothriocephalus decipiens (Diesing) y su larva Sparganum reptans en el Uruguay. Rev. Med. Vet. 1926, 2, 433-434.

18. Dei-Cas, E.; Rodríguez, N.; Botto, C.; Osimani, J.J. Larvas plerocercoides de Spirometra (Dibothriocephalidae) en el hombre y en animales silvestres de Uruguay. Rev. Inst. Med. Trop. Sao Paulo 1976, 18, 165-172.

19. Borteiro, C.; Castro, O.; Sabalsagaray, M.J.; Kolenc, F.; Martínez Debat, C.; Ubilla, M. Spargana in the Neotropical frog Hypsiboas pulchellus (Hylidae) from Uruguay. North-West J. Zool. 2015, 11, 171-173.

20. Osimani, J.J.; Peyrallo, R. Segundo caso de esparganosis encontrado en América del Sur. Primer caso descrito en el Uruguay. Arch. Urug. Med. Cir. Espec. 1954, 44, 139-148. [PubMed]

21. Bowles, J.; Blair, D.; McManus, D.P. Genetic variants within the genus Echinococcus identified by mitochondrial DNA sequencing. Mol. Biochem. Parasitol. 1992, 54, 165-173. [CrossRef]

22. Kumar, S.; Stecher, G.; Tamura, K. MEGA7: Molecular evolutionary genetics analysis version 7.0 for bigger datasets. Mol. Biol. Evol. 2016, 33, 1870-1874. [CrossRef] [PubMed]

23. Ronquist, F.; Teslenko, M.; van der Mark, P.; Ayres, D.L.; Darling, A.; Höhna, S.; Larget, B.; Liu, L.; Suchard, M.A.; Huelsenbeck, J.P. MrBayes 3.2: Efficient Bayesian phylogenetic inference and model choice across a large model space. Syst. Biol. 2012, 61, 539-542. [CrossRef] [PubMed]

24. Petrigh, R.S.; Scioscia, N.P.; Denegri, G.M.; Fugassa, M.H. Cox-1 gene sequence of Spirometra in Pampas foxes from Argentina. Helminthologia 2015, 52, 355-359. [CrossRef]

25. Ruas, J.L.; Muller, G.; Farias, N.A.R.; Gallina, T.; Lucas, A.S.; Pappen, F.G.; Sinkoc, A.L.; Brum, J.G.W. Helminths of Pampas fox Pseudalopex gymnocercus (Fischer, 1814) and of Crab-eating fox Cerdocyon thous (Linnaeus, 1766) in the Southern of the State of Rio Grande do Sul, Brazil. Rev. Bras. Parasitol. Vet. 2008, 17, 87-92. [CrossRef] [PubMed]

26. González, E.M.; Martínez-Lanfranco, J.A. Mamíferos de Uruguay. Guía de Campo e Introducción a su Estudio y Conservación; Vida Silvestre, Museo Nacional de Historia Natural, Ediciones de la Banda Oriental: Montevideo, Uruguay, $2010 ;$ p. 463.

27. Arrabal, J.P.; Pérez, M.G.; Arce, L.F.; Kamenetzky, L. First identification and molecular phylogeny of Sparganum proliferum from endangered felid (Panthera onca) and other wild definitive hosts in one of the regions with highest worldwide biodiversity. Int. J. Parasitol.: Parasites Wildl. 2020, 13, 142-149. [CrossRef] [PubMed] 